\title{
Efecto de la Microencapsulación sobre las Propiedades Reológicas y Fisicoquímicas del Yogurt Blando
}

\author{
Rafael E. González Cuello(1)* Jaime Pérez Mendoza(1), Néstor A. Urbina Suarez ${ }^{(2)}$ \\ (1) Univ. de Cartagena, Piedra de Bolívar - Av Del Consulado, Calle 30 NN$^{\circ}$ 48-157, Cartagena, Colombia. \\ (e mail: rgonzalezc1@unicartagena.edu.co) \\ (2) Universidad Francisco de Paula Santander, Departamento de Medio Ambiente. Av Gran Colombia \\ №12E - 96, Barrio Colsag., Cúcuta, Norte de Santander, Colombia
}

${ }^{*}$ Autor a quien debe ser dirigida la correspondencia

Recibido Abr. 4, 2014; Aceptado Jun. 26, 2014; Versión final recibida Ago. 15, 2014

\begin{abstract}
Resumen
En este trabajo se estudió la influencia de la microencapsulación de Lactobacillus acidophilus empleando un sistema gelificante binario, en la obtención de yogures blandos, evaluando los parámetros fisicoquímicos y reológicos después del proceso de incubación. Los resultados obtenidos mostraron que la microencapsulación de $L$. acidophilus incrementa la viscosidad y carácter visco elástico del yogurt. Sin embargo, el análisis sensorial llevado a cabo no mostró diferencias entre los yogures obtenidos con $L$. acidophilus microencapsulado y en estado libre. En cuanto a los análisis fisicoquímicos, los cambios en los valores de lactosa, grasa y proteína sugieren una mayor actividad metabólica por parte de Lactobacillus acidophilus microencapsulado, lo cual se evidencia por el mayor número de células bacterianas obtenidas. Por tal motivo, la microencapsulación bacteriana puede ser una técnica interesante para llevar a cabo la inclusión de bacterias probióticas en sistemas alimentarios ácidos, sin ocasionar pérdida de los atributos sensoriales del producto alimenticio.
\end{abstract}

\section{Microencapsulation Effects on the Rheological and Physico- chemical Properties of Soft Yoghurt}

\begin{abstract}
In this paper the influence of Lactobacillus acidophilus microencapsulation using a gelling binary system, in obtaining of soft yogurts, was studied, evaluating bromatological and rheological parameters. The results show that $L$. acidophilus microencapsulation increases viscosity and viscoelastic yogurt characteristics. However, the sensory analysis conducted did not show differences between yoghurt elaborated with $L$. acidophilus microencapsulated and yoghurt in free state. With respect to the physicochemical analysis, changes in the lactose, fat and protein values suggest an increase in the metabolic activity by L. acidophilus microencapsulated, which is evidenced by the increasing number of bacterial cells obtained at the end of the incubation period. Therefore, bacterial microencapsulation can be an interesting technique to perform the inclusion of probiotic bacteria in acidic food systems, without causing loss of the sensory attributes of the food product.
\end{abstract}

Keywords: soft yogurt, microencapsulation, rheological properties, bromatological properties 


\section{INTRODUCCIÓN}

El yogurt por su presencia en el mercado internacional y su elevado consumo, es el producto lácteo fermentado más importante a nivel industrial (Özer y Kimarci, 2010; Bakirci y Kavaz, 2008). Los desarrollos metodológicos sobre la elaboración del yogurt han sido llevados a cabo principalmente siguiendo el proceso tradicional sobre la leche de vaca, incluyendo: estandarización, pasteurización a $90^{\circ} \mathrm{C}$ por $10-30$ min, homogeneización y enfriamiento a $45-47^{\circ} \mathrm{C}$, inoculación con el cultivo iniciador, incubación a $40^{\circ} \mathrm{C}$, rápido enfriamiento a $4-7^{\circ} \mathrm{C}$ y empacado final (Tamime y Robinson, 2000). Por tal motivo, resulta interesante estudiar la calidad del yogurt desde otras perspectivas que correlacionen algunos factores que afecten la estructura del producto lácteo.

Una de las maneras de evaluar la calidad de un producto alimentario, es a través de la caracterización reológica (Fangary et al. 1999; Karoui et al. 2003), la cual es correlacionada con la textura, los atributos sensoriales y los cambios microestructurales que tienen lugar en los productos alimenticios (Shoemaker et al. 1992). La reología es una disciplina científica que se dedica al estudio de la deformación y flujo de los materiales (Steffe, 1996). Existen varias razones para justificar el estudio del comportamiento reológico de los alimentos, entre las cuales se encuentran: (1) la contribución al conocimiento de la estructura de los alimentos, (2) control de procesos y (3) ayuda al diseño de máquinas (Méndez, 2001). En reología, los métodos para determinar las funciones viscoelásticas lineales son estáticos y dinámicos, los cuales se caracterizan por ser de bajo esfuerzo o deformación.

En los ensayos reológicos dinámicos, las muestras se someten a un movimiento que varía armónicamente con el tiempo (movimiento oscilatorio), aunque solo se pueden aplicar deformaciones que no excedan el intervalo de viscoelasticidad lineal, los cuales harían una recuperación completa imposible. Se aplica de forma oscilatoria una velocidad de cizalla sobre un material y se mide la respuesta del esfuerzo y del ángulo de fase entre el esfuerzo y la deformación. Esta prueba corresponde al estado de la viscoelasticidad lineal, si el esfuerzo es linealmente proporcional a la deformación aplicada y si la respuesta del esfuerzo es en forma de una onda sinusoidal (Barnes, 2000). Para el caso de un sólido elástico la onda está en fase con la velocidad de cizalla aplicada. En el caso de un líquido ideal existe un desfase de $90^{\circ}$. Mientras que en los fluidos viscoelásticos el ángulo de desfase comprende entre 0 y $90^{\circ}$. Estos ensayos permiten determinar la proporción entre la componente elástica (G') y viscosa (G") de un material y establecer en qué medida se comporta como un sólido o como un líquido. Si G' es mayor que G" el material se comportará como un sólido; en la cual, la deformación será esencialmente elástica o recuperable. Sin embargo, si G" es mayor que G', la energía usada para deformar el material es disipada y el material se comportará como un líquido (Tabilo-Munizaga y Barbosa-Cánovas, 2005). G' se define como el esfuerzo en fase con la deformación, dividida por la deformación, en una prueba sinusoidal. Es una medida de la energía almacenada y recuperada por el material en un ciclo. Mientras que G" es el esfuerzo desfasado $90^{\circ}$ respecto a la deformación, dividida por la deformación, en una prueba de deformación sinusoidal. Es una medida de la energía disipada como calor por el material en un ciclo. Otra función usada para describir el comportamiento viscoelástico de materiales es la tangente del ángulo de desfasamiento denominado tan $\delta$ que es también una función de la frecuencia (Sffete, 1996). La tan $\delta$ indica la relación entre la cantidad de energía disipada y la energía almacenada, es decir entre la porción viscosa y elástica de la muestra (Méndez et al. 2001).

Los parámetros reológicos en general pueden ser afectados por el crecimiento de las bacterias utilizadas durante la fermentación; ya que en esta etapa se producen cambios en la composición nutricional del producto lácteo fermentado (consumo de lactosa y producción de ácidos) y se originan metabolitos tales como acetaldehído, diacetilos, ácido láctico y otros compuestos orgánicos que contribuyen enormemente con las características sensoriales del yogurt, pero que pueden afectar la viabilidad de la bacteria de interés, conllevando a una disminución en las actividades enzimáticas de la bacteria probiótica por efecto de la acumulación de dichos metabolitos.

Los probióticos, son microorganismos vivos, los cuales producen efectos benéficos en la salud de los consumidores. Los beneficios terapéuticos percibidos han llevado a incrementar la proporción de bacterias probióticas, tales como Lactobacillus sp en productos lácteos como el yogurt. Para lograr los efectos benéficos, los probióticos deben ser metabólicamente estables y activos, tanto en el producto alimenticio, como en el huésped (Kailasapathy y Chin, 2000). Varios reportes (Shah, 2000, Lourens-Hatting y Viljoen, 2001) han mostrado que la viabilidad de bacterias probióticas en el yogurt resulta ser menor al umbral terapéutico $\left(10^{8} \mathrm{UFC} / \mathrm{mL}\right)$, este umbral corresponde a la cantidad necesaria de microorganismos probióticas requerida para que los efectos benéficos sean percibidos por el huésped (López-Rubio et al. 2006). La supervivencia de microorganismo probióticos como Lactobacillus acidophilus (Krasaekoopt y Watcharapoka, 2014) depende de las condiciones de estrés ambiental tales como: producción de peróxidos, producción de ácido láctico y acético, disponibilidad de nutrientes y temperatura de incubación (Gregurek, 1999). 
Por ende, una técnica que permita aumentar o mantener la viabilidad de microorganismos probióticos resulta de gran interés. La microencapsulación de células bacterianas ha ganado atención con el fin de potenciar la viabilidad de bacterias probióticas en productos ácidos como el yogurt (Godward y Kailasapathy, 2003, Krasaekoopt et al. 2003). La microencapsulación, es una técnica que le permite a un material sensible ser empacado y protegido de las condiciones ambientales adversas. Diversos materiales de interés biológico han sido microencapsulados, desde pequeñas moléculas y proteínas hasta células bacterianas, levaduras y animales (Borgogna et al. 2010).

Los materiales utilizados en los procesos de microencapsulación son principalmente polisacáridos (Ibarguren et al. 2012). Dentro de estos polisacáridos se encuentran los alginatos y la goma gelana. Los alginatos son ampliamente utilizados en la industria alimentaria debido a sus propiedades gelificantes, viscosificantes y atoxicas. Químicamente los alginatos son copolimeros lineales aniónicos compuestos de $\beta$ $D$ ácido manuronico $(M)$, y $\alpha$-L ácido guluronico $(G)$ unidos por enlace $\beta$ 1-4 y es estructurado por bloques que pueden ser homopolimericos ( $M \circ G$ ) o heteropolimericos (MG) (Lee y Mooney, 2012). Una de las aplicaciones más importantes de los alginatos en biotecnología, es la habilidad que tienen para formar geles estables a través de la interacción de dos cadenas adyacentes $(\mathrm{G})$ con el $\mathrm{Ca++}$ formando zonas de unión que estabilizan la estructura del gel (Fabich et al. 2012) esta estructura generalmente puede ser utilizada como microcápsula. La goma gelana es un heteropolisacarido lineal aniónico compuesto de unidades de repetición de un tetrasacárido (1-3 $\beta$ D glucosa, 1,4 $\beta$ D ácido glucuronico, 1,4 $\beta$ D glucosa, $\alpha$-L ramnosa) y al igual que los alginatos, la goma gelana también puede formar geles en presencia de cationes (González et al. 2012).

Por tanto lo mencionando anteriormente, la microencapsulación puede ser utilizada para disminuir las pérdidas celulares durante el procesamiento de alimentos, así como reforzar la viabilidad de las bacterias de interés (Capela et al. 2006). Aunque hay estudios sobre la microencapsulación de Lactobacillus acidophilus (Shoji et al. 2013), no existe información concerniente al uso de mezclas de polisacáridos aniónicos como agentes encapsulantes incorporados en sistemas alimentarios evaluando los cambios reológicos y fisicoquímicos que tengan lugar por efecto de la microencapsulación. El objetivo del presente trabajo fue evaluar el efecto de la microencapsulación de Lactobacillus acidophilus utilizando un sistema gelificante binario compuesto por gelana y alginato sobre las propiedades fisicoquímicas y reológicas del yogurt blando.

\section{MATERIALES Y MÉTODOS}

Leche fue adquirida durante la primavera en hatos ganaderos cercanos al estado de México y tenía la siguiente composición: $3.6 \%$ de proteína, $3.8 \%$ de grasa, $4.9 \%$ de lactosa y un pH de 6.9 . El cultivo láctico de Lactobacillus acidophilus NCFM fue comprado a Danisco Mexico. El alginato y la goma gelana (Kelcogel F) suministrados por modernist pantry (USA). El ácido cítrico fue proporcionado por Tecnas S.A (Colombia). El agar MRS fue obtenido de Oxoid (Australia) y finalmente el $\mathrm{CaCO} 3$ por Merck (México).

\section{Preparación del cultivo}

Lactobacillus acidophilus fue subcultivado en caldo MRS a $37^{\circ} \mathrm{C}$ por $24 \mathrm{~h}$. Posteriormente $0,2 \mathrm{~mL}$ de la suspensión microbiana fue inoculada tres veces en tubos con $7 \mathrm{~mL}$ de $10 \%(\mathrm{p} / \mathrm{v})$ de leche en polvo reconstituida. Luego se determinó el número de unidades formadoras de colonias (UFC/mL) en agar MRS.

\section{Microencapsulación}

Las microcápsulas fueron preparadas a través del proceso de gelación iónica interna; esta técnica se basa en la formación de una emulsión agua/aceite. La fase acuosa fue preparada mezclando $1 \mathrm{~mL}$ de la suspensión celular ( $10^{9} \mathrm{cel} / \mathrm{mL}$ de Lactobacillus acidophilus) con $99 \mathrm{~mL}$ de la dispersión de alginato y gelana (en una proporción $50 / 50 \mathrm{p} / \mathrm{p}$ previa esterilización en autoclave a $121^{\circ} \mathrm{C}$ durante $15 \mathrm{~min}$ ). El carbonato de calcio fue utilizado como donador de $\mathrm{Ca}^{++}$en una proporción de $30 \mathrm{mM}$ de $\mathrm{Ca}^{++}$. Posteriormente la dispersión (Lactobacillus acidophilus, AS, $\mathrm{GBA}$ y $\mathrm{CaCO}_{3}$ ) se adicionó en aceite vegetal conteniendo un $2 \%$ $\mathrm{v} / \mathrm{v}$ de surfactante (Span 80) a una relación (1:2) bajo agitación constante (800 rpm), posterior a los 15 minutos, se incorporó ácido cítrico al sistema hasta alcanzar un $\mathrm{pH}$ de $4.2 \mathrm{con}$ el fin obtener las microcápsulas por gelificación de los biopolimeros. Finalmente el aceite es retirado por adsorción y las microcápsulas contenidas en la fase acuosa son centrifugadas a $5000 \mathrm{rpm} / 10 \mathrm{~min}$ dos veces con disolución salina y almacenadas a $4^{\circ} \mathrm{C}$ hasta su uso.

\section{Determinación del diámetro de las microcápsulas}

$20 \mu \mathrm{L}$ de las muestras fueron utilizadas para determinar el diámetro de las microcápsulas. La muestra fue diluida en disolución salina estéril en un portaobjetos, para su análisis en un microscopio óptico Leica 
DM500 integrado a una cámara. Las micrografías obtenidas fueron procesadas con ayuda del programa de cómputo Image Pro-Plus ver. 5.1

\section{Elaboración del yogurt}

La leche fue previamente tratada térmicamente con el fin de eliminar la microbiota contaminante, posteriormente fue dividida en dos lotes. La leche fue enfriada a $37^{\circ} \mathrm{C}$ y luego se adicionó la misma cantidad de Lactobacillus acidophilus ( $\left.10^{9} \mathrm{UFC} / \mathrm{mL}\right)$ en estado libre y microencapsulado a cada lote y bajo condiciones de asepsia con el fin de evitar contaminaciones. Finalmente ambos lotes fueron sometidos a un proceso de incubación durante 7 horas. Obteniendo de esta manera los dos tipos de yogurt: yogurt con el microorganismo en estado libre (YML) y con el microorganismo microencapsulado (YMM).

\section{Determinación de la viabilidad de Lactobacillus acidophilus}

Una vez trascurrido el tiempo de incubación, se tomaron $11 \mathrm{~mL}$ del yogurt y se adicionaron en $99 \mathrm{~mL}$ de agua de peptona, posteriormente se realizaron diluciones seriadas consecutivas y finalmente se enumeró el crecimiento de microorganismos en agar MRS. Para la liberación de los microorganismos presentes en las microcápsulas, se llevó a cabo la maceración de las microcápsulas con ayuda de una varilla de vidrio.

\section{Determinación de parámetros fisicoquímicos}

Estos análisis fueron llevados a cabo conforme lo establecen los métodos de la AOAC, (2003). La proteína fue analizada por el método de Kjedahl (AOAC 920.152), grasa (AOAC 31.4.32), humedad (AOAC 920.151), cenizas por secado en horno (AOAC 940.26), lactosa por el método de Lane y Eynon (AOAC 923.09, 920.183b) el pH fue determinado con un potenciómetro digital (Beckman, USA). Todos los análisis fueron realizados por triplicado.

\section{Comportamiento al flujo}

La determinación de las curva de flujo y el comportamiento de la viscosidad fueron realizados posterior al proceso de incubacion, en un reómetro de bajo esfuerzo LS 100 (Paar Physica) utilizando una geometría de cilindros concéntricos DG1 de $48 \mathrm{~mm}$ de diámetro y $36 \mathrm{~mm}$ de longitud. Todas las pruebas se llevaron a cabo por triplicado y ajustadas al modelo de Ostwald-de-Waele.

$\sigma=K \gamma^{n}$

donde $\sigma$ es el esfuerzo de cizalla $(\mathrm{Pa})$, y es la velocidad de cizalla $\left(\mathrm{s}^{-1}\right), \mathrm{K}$ es el índice de consistencia $(\mathrm{Pa}$ $\mathrm{s}^{n}$ ) y $\mathrm{n}$ es el índice de comportamiento al flujo (adimensional).

\section{Estudio reológico dinámico}

Para realizar este análisis en los yogures (YMM y YML) se utilizó la geometría de placa paralela (PP20) de $20 \mathrm{~mm}$ de diámetro y un gap de $3 \mathrm{~mm}$. Las muestras fueron colocadas en el plato inferior (peltier) y el gap fue ajustado. Las determinaciones se llevaron a cabo en un rango de velocidades de cizalla comprendidas entre $5.00 \times 10^{-5}$ y $1.00 \times 10^{3} \mathrm{~s}^{-1}$ y esfuerzos de cizalla entre $6.370 \times 10^{-1}$ y $6.370 \times 10^{3} \mathrm{~Pa}$. Un barrido de amplitud fue llevado a cabo con torques de $1 \times 10^{-3}$ a $1 \times 10^{1} \mathrm{mNm}$ para determinar la zona de viscoelasticidad lineal ( $Z V L)$ que es obtenida cuando el módulo de almacenamiento (G') y el módulo de pérdida (G") son independientes de la amplitud. Posteriormente un barrido de frecuencia entre $0.01 \mathrm{y} 1 \mathrm{~Hz}$, fue llevado a cabo para determinar el comportamiento de las componentes elásticas y viscosas en función de la frecuencia.

\section{Evaluación sensorial del yogurt}

La evaluación sensorial de los yogures fue llevada a cabo después de transcurrida la etapa de incubación. El panel consistió de 30 jueces no entrenados que evaluaron las muestras de yogurt codificadas. La evaluación sensorial (color, sabor, consistencia y aceptabilidad global) se basó en la escala hedónica de 10 puntos (1, me disgusta extremadamente; 10 me gusta extremadamente). Las muestras fueron presentadas en contenedores plásticos libres de olores, se utilizó agua para el lavado de la boca entre muestras. Se presentaron tres muestras a cada panelista.

\section{Análisis estadístico}

Los datos fueron analizados mediante análisis normal de varianza (ANOVA un factor) con el fin de establecer diferencias estadísticas significativas $(p<0.05)$ entre las muestras analizadas. Para tal fin se utilizó el programa de computo SPSS (ver 17.0 para Windows) empleando la prueba de tukey. 


\section{RESULTADOS Y DISCUSIÓN}

\section{Diámetro de las microcápsulas}

Las microcápsulas obtenidas estudio mostraron un comportamiento unimodal; esto se puede explicar por la lenta liberación de los iones calcio por reacción de sustitución del carbonato de calcio a causa de la acidificación llevada a cabo por la adición de ácido cítrico. Los iones de calcio se ubican en los grupos carboxilos del polisacárido aniónico (gelana y alginato) iniciando el proceso de gelificación (Tang et al. 1997), teniendo el tiempo suficiente para obtener el tamaño y la forma de las microcápsulas finales. Con respecto al tamaño de las microcápsulas, estas presentaron valores de 15 a $75 \mu \mathrm{m}$ (figura 1) siendo este comportamiento similar el reportado por Kim et al. (2008) quienes obtuvieron diámetros de $75 \mu \mathrm{m}$ en microcápsulas elaboradas con alginato de sodio, cabe destacar que microcápsulas de diámetros inferiores a $80 \mu \mathrm{m}$ son deseadas a nivel industrial, ya que diámetros mayores pueden originar defectos texturales en el producto alimenticio que se utilicen y diámetros muy pequeños resultan en la disminución de la protección celular del microorganismo (Lacroix et al. 2005).

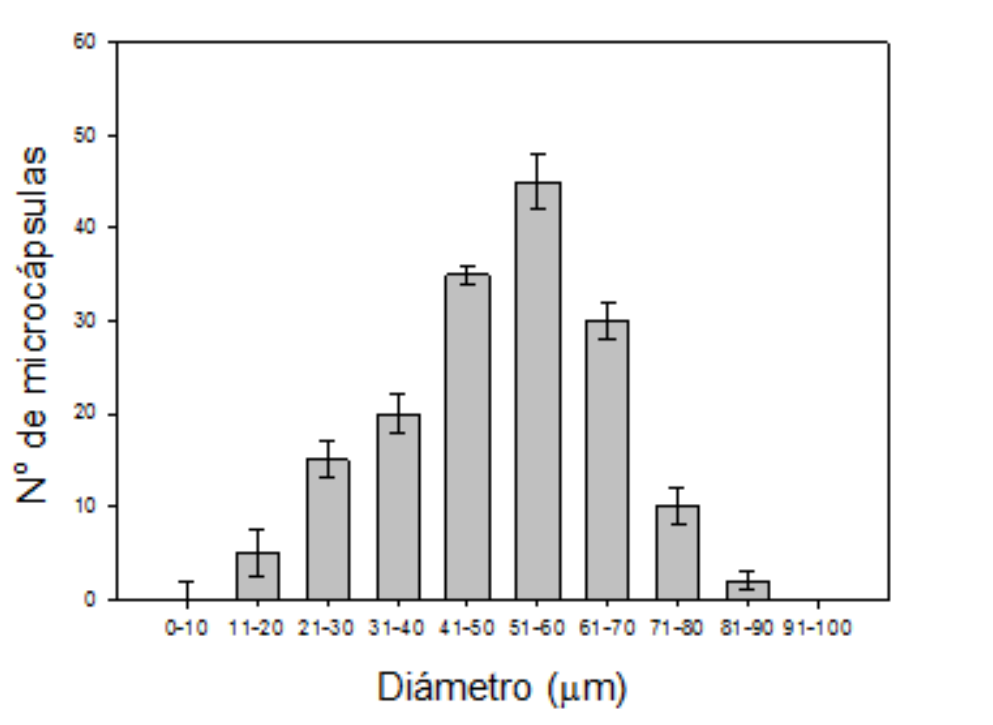

Fig. 1: Distribución de los diámetros de las microcápsulas obtenidas a base de gelana y alginato

\section{Viabilidad de Lactobacillus acidophilus en yogurt}

Los resultados mostraron que había una disminución de la viabilidad de L. acidophilus en estado libre mientras que las células de L. acidophilus microencapsuladas presentaban un ligero aumento. La disminución de la viabilidad bacteriana en el yogurt, es atribuida principalmente a los bajos valores de $\mathrm{pH}$, por lo cual, la microencapsulación parece ser la tecnología indicada para proteger las células bacterianas de medios ambientes adversos (Kailasapathy, 2002). La supervivencia de microorganismo probióticos como Lactobacillus acidophilus (Krasaekoopt y Watcharapoka, 2014) depende de las condiciones de estrés ambiental tales como: producción de peróxidos, producción de ácido láctico y acético, disponibilidad de nutrientes y temperatura de incubación (Gregurek, 1999). Teniendo esto en consideración la microcápsula proporciona una barrera física para que estos metabolitos no entren en contacto directamente con la célula bacteriana, aumentando por consiguiente la viabilidad del microorganismo. Los resultados de este estudio, mostraron que había un incremento $(2 \mathrm{log})$ en la viabilidad de $L$. acidophilus, debido a la microencapsulación. Godward y Kailasapathy (2003) también reportaron que la microencapsulación mejora la viabilidad de las bacterias probióticas en el yogurt; por tal motivo, esta bebida puede ser utilizada como vehículo para la incorporación de probióticos en la dieta. Existe una evidencia creciente en que la microencapsulación es útil en la protección de cultivos probióticos destinados a ser adicionados a alimentos (Krasaekoopt et al. 2003; Sultana et al, 2000). Krasaekoopt et al. 2003 reportaron que la microencapsulación puede facilitar la manufactura de productos lácteos fermentados, debido a que las bacterias tienen mayor estabilidad durante el almacenamiento.

\section{Análisis fisicoquímicos}

Los análisis fisicoquímicos de los yogures obtenidos, se presentan en la tabla 1. Se aprecia una leve disminución significativa $(\mathrm{p}<0.05)$ en los niveles de grasas, proteínas y lactosa en los yogures obtenidos con L. acidophilus microencapsulado, esto se debe principalmente al crecimiento de la bacteria observado en la 
prueba de viabilidad. Los valores de grasas y proteínas obtenidos en este estudio difieren a los reportados por Sendra et al. (2010) quienes obtuvieron valores de grasa menores al $0.1 \%$ y niveles de proteína cercanos al $5 \%$ en yogures enriquecidos con fibra de naranja. Con respecto a los niveles de lactosa, se presentaron mayores concentraciones en los YML (4.7\%) que los YMM (4.52\%) este comportamiento puede ser atribuido al efecto protector que ejercen las microcápsulas de los factores ambientales generados durante la incubación (acidez, producción de metabolitos, etc.), lo cual se refleja en el mayor número de células de L. acidophilus microencapsulado obtenidos al final del periodo de incubación. Las concentraciones de lactosa en YMM presentaron diferencia estadística significativa $(\mathrm{P}<0.05)$ en comparación con los YML, lo cual indica que L. acidophilus microencapsulado desdobla mayor cantidad de lactosa con la respectiva producción de ácido láctico, esto se pone en evidencia con el menor valor de pH obtenido en los YMM y es corroborado por el mayor número de microorganismos microencapsulados obtenidos al final del periodo de incubación en los YMM.

Los valores de $\mathrm{pH}$ del yogurt elaborado con $L$. acidophilus microencapsulado $(4.38)$ fue menor $(\mathrm{P}<0.05)$ que el yogurt inoculado con el microorganismo en estado libre (4.50). Resultados similares fueron reportados por Kailasapathy, (2006) quien obtuvo valores de pH 4.48 en yogurt elaborado con mezclas de Lactobacillus acidophilus y Bifidobacterium lactis microencapsulados, mientras que yogures obtenidos microorganismos en estado libre el $\mathrm{pH}$ fue de 4.52, este comportamiento se debe a una mayor acidificación como consecuencia del consumo de lactosa por parte de las bacterias probióticas, las cuales normalmente son productoras de ácido (Marshall y Tamime, 1997) específicamente, el género Lactobacillus (Shah, 2000). Esta acidificación ha sido descrita como deseable por algunos autores (Cruz et al. 2013) debido a que mejora los atributos sensoriales de la bebida. Sin embargo, una sobre acidificación puede disminuir la viabilidad de los probióticos inoculados.

Con respecto a los niveles de cenizas, los yogures elaborados con $L$ acidophilus presentaron las mayores concentraciones $(0.84 \%)$ resultados similares fueron obtenidos por Sendra et al. (2010) quienes reportaron niveles de cenizas entre 0.68 y $0.81 \%$ en yogures con adición de fibra. Los niveles de ceniza obtenidos en el yogurt elaborado con el microorganismo microencapsulado, probablemente se debe a la adición de goma gelana, alginato de sodio y Carbonato de Calcio en forma de microcápsulas; estos resultados concuerdan con los reportados previamente por González et al. (2011) que quesos tipo Manchego elaborados con microorganismos microencapsulados. Finalmente en cuanto al contenido de humedad, se observó que los valores obtenidos en los YMM fueron significativamente $(P<0.05)$ mayores que los encontrados en los YML como consecuencia de la naturaleza hidrofilica de los polímeros utilizados en la elaboración de las microcápsulas.

Tabla 1. Análisis fisicoquímicos de los yogures analizados

\begin{tabular}{|c|c|c|}
\hline Parámetros & YMM & YML \\
\hline Proteína (\%) & $2.73 \pm 0.7^{\mathrm{a}}$ & $2.92 \pm 0.7^{\mathrm{b}}$ \\
\hline Grasa (\%) & $3.21 \pm 0.3^{\mathrm{a}}$ & $3.38 \pm 0.4^{\mathrm{b}}$ \\
\hline Cenizas (\%) & $0.84 \pm 0.1^{\mathrm{a}}$ & $0.48 \pm 0.1^{\mathrm{b}}$ \\
\hline Lactosa (\%) & $4.52 \pm 0.4^{\mathrm{a}}$ & $4.70 \pm 0.4^{\mathrm{b}}$ \\
\hline Humedad (\%) & $79.15 \pm 0.6^{\mathrm{a}}$ & $76.77 \pm 0.3^{\mathrm{b}}$ \\
\hline $\mathrm{pH}$ & $4.38 \pm 0.0^{\mathrm{a}}$ & $4.50 \pm 0.0^{\mathrm{b}}$ \\
\hline
\end{tabular}

\section{Estudios reológicos de los yogures}

En la figura 2 se muestran las curvas de flujo para los yogures elaborados con L. acidophilus microencapsulado y en estado libre, donde puede apreciarse que ambos yogures mostraron un comportamiento no newtoniano tipo reofluidificante (Fangary et al. 1999), este comportamiento también fue observado por Cruz et al. (2013) en yogures prebióticos obtenidos por la adición de oligofructosa y por Sendra et al. (2010) en yogures adicionados con fibra de naranja. Las curvas de incremento en la velocidad de deformación fueron modeladas matemáticamente usando la ecuación de Ostwald-de-Waele obteniendo sus respectivos parámetros (ver tabla 2). Todas las muestras mostraron claramente un comportamiento reofluidificante con índices de flujo menores a la unidad $(n<1)$, aunque en ambos yogures se presentaron diferencias estadísticas significativas $(\mathrm{P}<0.05)$ como consecuencia de la microencapsulación de $L$. acidophilus. Con respecto al índice de consistencia los yogures elaborados con L. acidophilus microencapsulado presentaron diferencia estadística significativa $(\mathrm{P}<0.05)$ con respecto a los $\mathrm{YML}$. Generalmente para incrementar la consistencia de un yogurt en la industria láctea tiende a seguir algunos de los siguientes procesos: (1) suplementar la leche con productos lácteos no grasos, (2) homogeneización de la leche y (3) la aplicación de diversos tratamientos térmicos para desnaturalizar las proteínas del suero para permitir una mejor interacción (Vercet et al. 2002). Claramente en las condiciones utilizadas en este trabajo, los enunciados anteriores no pueden ser responsables del incremento de la consistencia del yogurt 
elaborado con el microorganismo microencapsulado, debido a que ninguno de estos factores fue evaluado, ya que no fue este el objetivo de la presente investigación. Los resultados obtenidos revelan la posibilidad de incrementar la consistencia de los yogures sin la necesidad de adicionar solidos externos, únicamente con la adición de microcápsulas, las cuales mejoran la viabilidad de la bacteria probiótica.

En cuanto a los valores de viscosidad aparente estimados, se apreció un incremento significativo $(p<0.05)$ con la adición de microcápsulas (figura 3); dicho comportamiento obedece al cambio que ejerce la microencapsulación en el crecimiento de $L$. acidophilus, aunque puede no se puede descartar el efecto de las interacciones entre las proteínas de la leche y la goma gelana (formación de complejos electrostáticos),(Picone y Cunha, 2010), ya que la estructura heterogénea del yogurt resulta de la interacción de las proteínas de la leche, así como las moléculas de grasa (Benezech y Maingonmat, 1994) aunque, estas últimas no han sido estudiadas a profundidad en su relación con polisacáridos aniónicos. Por otro lado, algunos autores han establecido que la influencia de varios factores durante el almacenamiento, tales como la capacidad de retención de agua (Soukoulis et al, 2009) y formación de pequeños agregados de microcristales (González et al. 2008) pueden tener cierto efecto en el comportamiento reológico de los sistemas alimentarios.

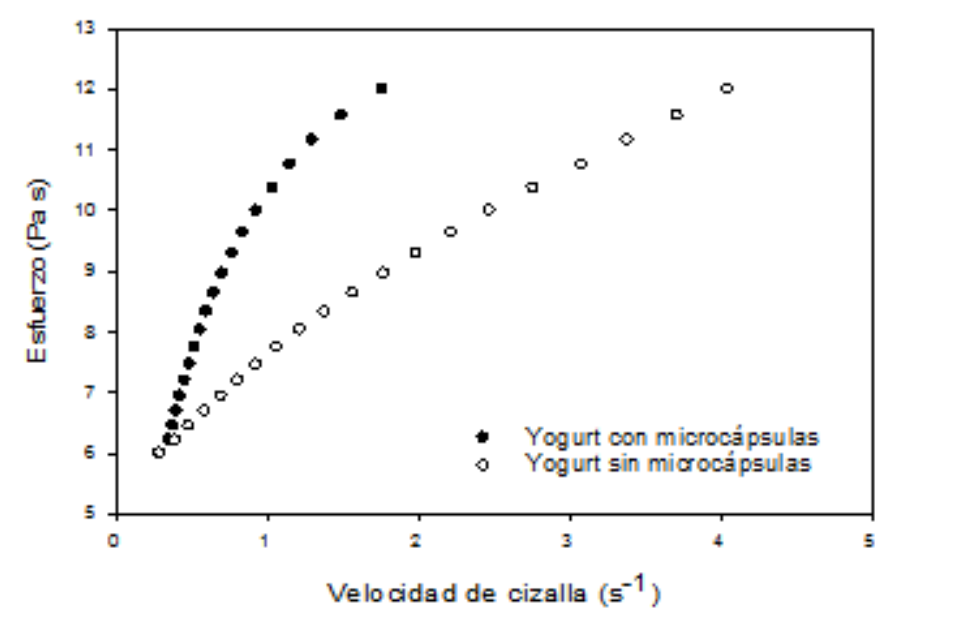

Fig. 2: Curvas de flujo de yogures obtenidos con el microorganismo microencapsulado y en estado libre

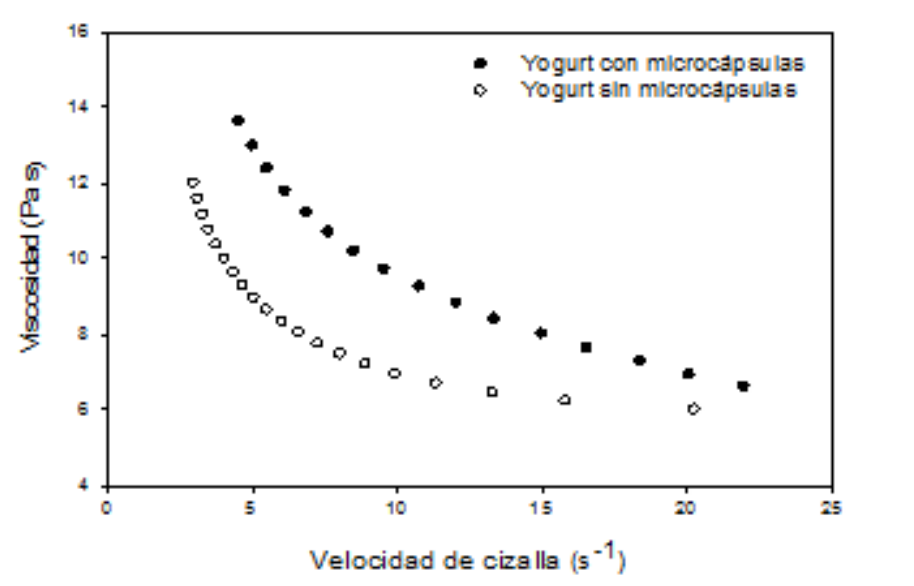

Fig. 3: Comportamiento de la viscosidad de los yogures analizados

El comportamiento reológico de un yogurt depende de la historia de cizalla a la cual haya sometido durante su procesamiento, por lo cual es factible que otros autores (Fangary et al. 1999; Ramirez-Sucre y VélezRuiz, 2013) hayan ajustado sus curvas de flujo a otros modelos que requieren un esfuerzo de fluencia (modelo de Herschel Bulkley). En la presente investigación no se apreció un esfuerzo de fluencia en los yogures evaluados, probablemente porque no se adicionaron sólidos (leche en polvo, etc) a la leche durante la elaboración del yogurt y el mencionado historial de cizalla. Igualmente, es importante destacar que la 
firmeza del gel de un yogurt también está relacionada con los sólidos totales y con el contenido de proteínas (Tamime, 2006).

Tabla 2. Parámetros reológicos del modelo Ostwald de Waele y coeficientes de correlación de los yogures estudiados

\begin{tabular}{|c|c|c|c|}
\hline Yogurt & $\mathrm{n}(-)$ & $\mathrm{K}\left(\mathrm{Pa} \mathrm{s}^{\mathrm{n}}\right)$ & $\mathrm{r}^{2}(-)$ \\
\hline $\mathrm{YMM}^{\mathrm{a}}$ & $0.45 \pm 0.81^{\mathrm{a}}$ & $25.44 \pm 0.52^{\mathrm{a}}$ & 0.99 \\
\hline YML & $0.53 \pm 0.72^{\mathrm{b}}$ & $18.254 \pm 0.63^{\mathrm{b}}$ & 0.99 \\
\hline
\end{tabular}

Media aritmética \pm desviación estándar. YMM representa el yogurt obtenido con L. acidophilus microencapsulado, YML es el yogurt elaborado con L. acidophilus en estado libre. Filas sin ninguna letra en común presentaron diferencias estadísticas significativas a un nivel de confianza del $95 \%$

Reología dinámica

En la figura 4 se presentan los valores de G' y G” en función de la frecuencia para los yogures estudiados. Se puede apreciar que existen diferencias cuantitativas en el espectro para las magnitudes de los parámetros viscoelásticos de los yogures, también se observa un incremento en ambos módulos al ir aumentando la frecuencia siguiendo un comportamiento constante, este comportamiento también fue apreciado por Ramirez-Sucre y Vélez-Ruiz, (2013) en yogures adicionados con caramelo.

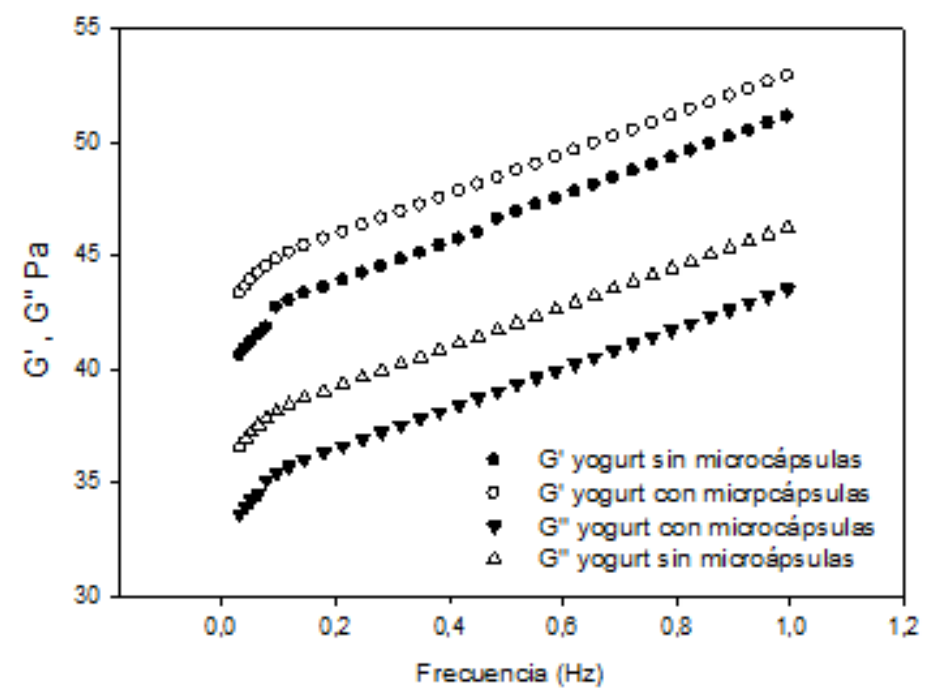

Fig. 4: Comportamiento de los módulos dinámicos (G' y G") en función de la frecuencia

Los valores de G' y G" mostraron dependencia de la frecuencia, G' fue mayor que G" en el rango de frecuencias estudiadas $(0.01-1.0 \mathrm{~Hz})$ para ambos yogures; lo que es característico de un gel débil, que es típico de los yogures (Meyer et al. 2011). Los mayores valores de G' se encontraron en el yogurt elaborado con $L$. acidophilus microencapsulado, esto concuerda con los valores obtenidos en la curva de flujo (fig. 2) donde se evidenció un incremento en la consistencia del yogurt. Los mayores valores de G' representan que el YMM tiene una estructura que requiere de mayores esfuerzos de cizalla para su deformación. Este comportamiento también fue observado por Acevedo et al. (2014) en sueros costeños elaborados en zonas del departamento de Bolivar- Colombia, estos autores atribuyen esta conducta a la formación de un gel por parte de las caseínas de la leche que atrapa la grasa presente.

La $\tan \delta$ es una medida adimensional que compara la cantidad de energía pérdida durante un ensayo oscilatorio con la cantidad de energía almacenada, indicando si predomina el carácter elástico o viscoso en un material. Los valores de tan $\delta$ para los yogures estudiados están representados en la figura 5 , donde se puede apreciar que el yogurt elaborado con $L$. acidophilus microencapsulado presenta la menor tan $\delta$ en todo el intervalo de frecuencia estudiado $(0.01-1.0 \mathrm{~Hz})$, lo cual indica que en este yogurt predominan más las propiedades elásticas que el yogurt elaborado con L. acidophilus en estado libre. Probablemente las caseínas forman con la grasa y proteínas del lactosuero estructuras más complejas, lo cual acentúa el carácter viscoelástico (Lucey et al. 1998). Igualmente se puede apreciar que los valores de tan $\delta$ es prácticamente constante indicando un comportamiento sólido consistente en el rango de frecuencia estudiado, este comportamiento también fue apreciado por Sendra et al. (2010) en yogures con fibra de naranja. 


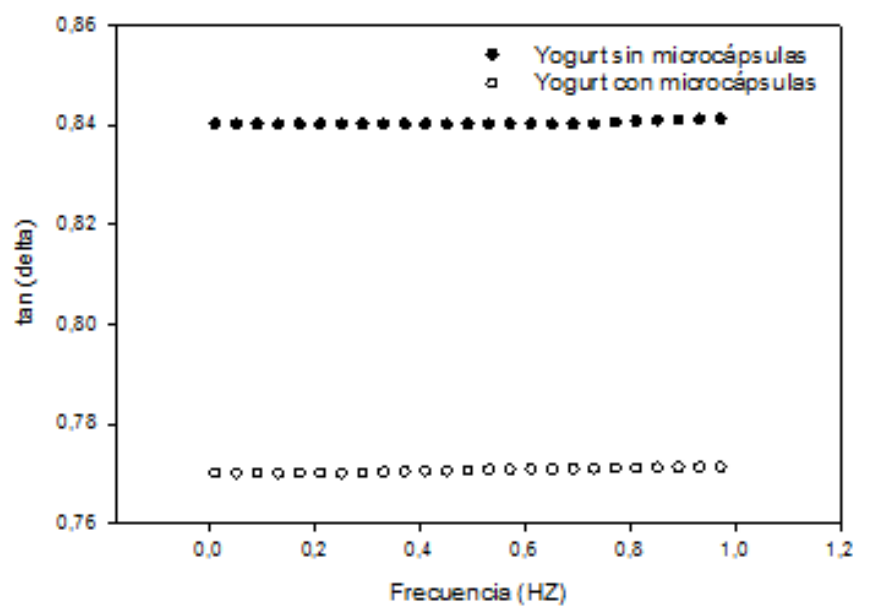

Fig. 5: Valores de la tangente del ángulo de fase $(\delta)$ en función de la frecuencia para los yogures analizados

Finalmente se puede decir que la presencia de microcápsulas acentúa la consistencia del yogurt; ya que el YMM presenta mayores valores en los módulos de almacenamiento, viscosidad e índice de consistencia en comparación con el yogurt elaborado con L. acidophilus en estado libre. Este comportamiento puede estar asociado al crecimiento de $L$. acidophilus y su consecuente consumo de lactosa, grasa y proteínas. Aunque no se debe descartar el efecto de los distintos tipos de interacción que se pueden presentar entre los polisacáridos aniónicos y las proteínas presentes en la leche.

Evaluación sensorial del yogurt

Los promedios de los puntajes obtenidos de todos los panelistas se muestran en la figura 6 . Los resultados muestran que no se encontraron diferencias estadísticas significativas $(P<0.05)$ en los atributos evaluados entre los YMM y lo YML. Se esperaba que la adición de microcápsulas al yogurt pudiera afectar la consistencia del yogurt, debido a que en este factor se presentaron variaciones desde el punto de vista reológico; sin embargo, los panelistas no lograron identificar las diferencias entre los yogures obtenidos con L. acidophilus libre y microencapsulado. Con respecto al color tampoco se presentaron diferencias estadísticas significativas entre los yogures evaluados, resultados similares fueron reportados por Kailasapathy (2006). Este autor manifiesta que las microcápsulas de alginato no ejercen cambios en la coloración del yogurt debido al color blanco de las mismas. Igualmente es posible que el pequeño tamaño de las microcápsulas evite los cambios en la coloración y apariencia de la bebida láctea aunque este autor no reportó los diámetros de las microcápsulas utilizadas. Al comparar los atributos sensoriales de los YML y YMM con un yogurt comercial, se presentaron diferencias estadísticas significativas $(P<0.05)$, esto se debe principalmente a que durante la elaboración de los yogures comerciales, se emplean mezclas de varios microorganismos y se adicionan mezclas de sólidos para contribuir al bouquet de esta bebida láctea, lo cual mejora la percepción sensorial por parte de los panelistas, sin embargo, el único atributo que no presentó diferencias estadísticas fue el color, esto obedece a que el yogur comercial utilizado era natural y no contenía colorantes.

\section{CONCLUSIONES}

La microencapsulación de L. acidophilus utilizando mezclas de polisacáridos aniónicos (goma gelana y alginato) incrementa desde un punto de vista reológico la consistencia del yogurt, sin embargo esta diferencia no fue apreciada por los panelistas en el análisis sensorial llevado a cabo entre los YML y YMM. Con respecto a los análisis fisicoquímicos, los cambios en los valores de lactosa, grasa y proteína sugieren un mayor crecimiento por parte de Lactobacillus acidophilus microencapsulado, lo cual se evidencia con el mayor número de células bacterianas obtenidas al final del proceso de incubación y como consecuencia del efecto protector que ejercen las microcápsulas contra la acidez presente en el yogurt. Por tal motivo, la microencapsulación bacteriana puede ser una técnica interesante para llevar a cabo la inclusión de bacterias probióticas en sistemas alimentarios ácidos, obteniendo elevadas viabilidades sin ocasionar grandes cambios en la apreciación sensorial del producto alimenticio.

\section{AGRADECIMIENTOS}

Los autores agradecen los conocimientos proporcionados por los doctores Juan Alfredo Salazar Montoya del CINVESTAV-México y Virginia Delgado Reyes de la UNAM-México así como del Ing Miguel Márquez Robles por sus explicaciones técnicas en el área reológica. 


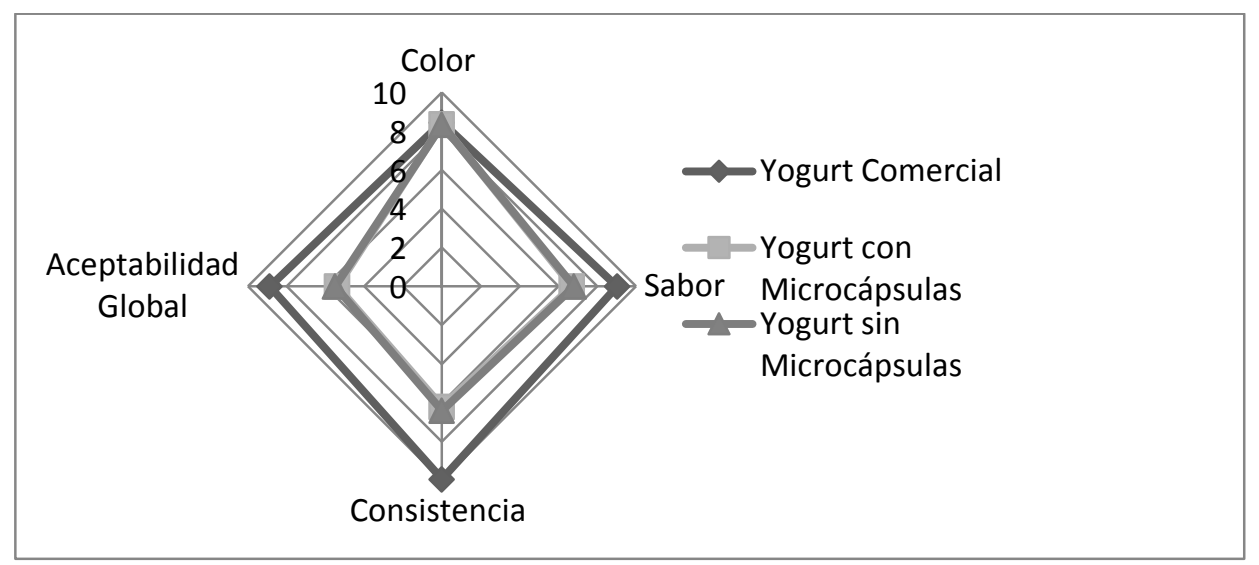

Fig. 6: Análisis sensorial de los yogures evaluados

\section{REFERENCIAS}

Acevedo, D. y otros dos autores, Caracterización reológica del suero costeño de Turbaco, Arjona, El Carmen de Bolivar y uno comercial (Colombia), Inf Tecnol, 25(3), 3-10 (2014).

AOAC, Association of official Methods of Analytical Chemistry Inc.Washington, USA., Chapter 32: 1, 5 y 14 (2005).

Bakirci, I. y A. Kavaz, An investigation of some properties of banana yogurts made with commercial ABT-2 starter culture during storage, Int J. Dairy Technol, 61(1), 270-276 (2008).

Barnes, H., A handbook of elementary rheology, 1a edition, 83-88, University of wales, Institute of non Newtonian fluid mechanics, Cardiff, Wales, UK (2000).

Borgogna, M. y otros cuatro autores, Food microencapsulation of bioactive compounds: Rheological and thermal characterization of non-conventional gelling system, Food Chem, 122(2), 416-423 (2010).

Benezech, I. y J. Maingonnat, Characterization of the rheological properties of yoghurt-a review, Journal of Food Eng, 21, 447-472 (1994).

Capela, P., y otros dos autores, Effect of cryoprotectants, prebiotics and microencapsulation on survival of probiotic organisms in yoghurt and freeze-dried yoghurt, Food Res. Int, 39(1), 203-211 (2006).

Cruz, A. y otros nueve autores, Developing a prebiotic yogurt: Rheological, physico-chemical and microbiological aspects and adequacy of survival analysis methodology, J. Food Eng, 114(1), 323-330 (2013).

Fabich, H. y otros autores, Microbial and algal alginate gelation characterized by magnetic resonance. J. Biotechnol, 161(3), 320-327 (2012).

Fangary, Y. y otros dos autores, Simulation of yogurt flow and prediction of its end-of-process properties using rheological measurements, Food Biop. Proces, 77(1), 33-39 (1999).

Godward, G. y K. Kailasapathy, Viability and survival of free, encapsulated and coencapsulated probiotic bacteria in yoghurt, Milk Science International (Milchwissenschaft), 58, 396-399 (2003).

González, L. y otros dos autores, Viscoelasticity of inulin starch-based dairy system. Influence of inulin average chain length, Food Hydrocol, 22 (1), 1372-1380 (2008).

González, R. Efecto de la concentración de gelana de alto y bajo acilo en la microencapsulación del cultivo iniciador Lactococcus lactis en la obtención de quesos tipo Manchego, Tesis de Doctorado, Departamento de Biotecnología y Bioingeniería, CINVESTAV, México D.F., México, (2011).

González, R. y otros tres autores, Rheological characterization and activation energy values of binary mixtures of gellan, Eur Food Res Technol, 234, 305-313 (2012).

González, R. y otros dos autores, Obtaining size-controlled microcapsules by ionic gelation with high and low acyl gellans containing Lactococcus lactis, Rev. Colomb. Biotecnol, 15(2), 70-80 (2013). 
Gregurek, L. Effect of level starter culture on viability of probiotics bacteria in yogurt, Mljekarstvo, 49(1), 3-8 (1999).

Ibarguren, C. y otros tres autores, Anti-Listeria monocytogenes activity of enterocins microencapsulated by ionic gelation, Food Hydrocol, 29(1), 21-26 (2012).

Kailasapathy, K. y J. Chin, Survival and therapeutic potential of probiotic organism with reference to Lactobacillus acidophilus abd Bifidobacterium sp, Inmmunol Cell Biol, 78, 80-88 (2000).

Kailasapathy, K. Microencapsulation of probiotic bacteria: technology and potential applications, Current Iss Interest in Microbiol, 3, 39-48 (2002).

Kailasapathy, K., Survival of free and encapsulated probiotic bacteria and their effect on the sensory properties of yoghurt, Food Sci Technol, 39, 1221-1227 (2006).

Karoui, R. y otros dos autores, Fluorescence spectroscopy: A tool for the investigation of cheese meltingcorrelation with rheological characteristics, Le Lait 83(1) 251-264 (2003).

Kim, S. y otros siete autores, Effect of microencapsulation on viability and other characteristics in Lactobacillus acidophilus ATCC 43121, WLT-Food Sci Technol, 41, 493-500 (2008).

Krasaekoopt, W. y otros dos autores, Review: Evaluation of encapsulation techniques of probiotic for yoghurt, Int Dairy J, 13, 3-13 (2003).

Krasaekoopt, W. y S. Watcharapoka, effect of addition of inulin and galactosachaccharude on the survival of microencapsulated probiotics in alginate beads coated with chitosan in simulated digestive system, yoghurt and fruit juice, Food Sci Technol, 57, 761-766 (2014).

Lacroix, C. y otros tres autores, Immobilised cell technologies for the dairy industry, Appl Cell Imm Biotechnol, 8B, 295-319 (2005).

Lee, K. y D. Mooney Alginate: Properties and biomedical applications. Progr Pol Sci, 37(1) 106-126 (2012).

Lopez-Rubio, A, y otros dos autores, Bioactive packaging: turning foods into healthier foods through biomaterials. Trends Food Sci Technol, 17, 567-575 (2006).

Lourens-Hattingh, A. y B. Viljoen, Review: Yoghurt as probiotic carrier food, Int Dairy J, 11, 1-17 (2001).

Lucey, J. y otros tres autores, Microstructure, permeability and appearance of acid gels made from skim milk, Food Hydrocol, 12(2), 159-165 (1998).

Marshall, V. y A. Tamime, Starter cultures employed in the manufacture of biofermented milks, Int Dairy J, 50, 35-39, (1997).

Mendez, M. y otros dos autores, Introduccion a la reología, primera ed. Instituto Politécnico Nacional, México D.F. $79-90$ p. (2001).

Meyer, D. y otros tres autores, Inulin as texture modifier in dairy products, Food Hydrocol, 25, 1881-1890. (2011).

Özer, B.H. y H.A. Kirmaci, Functional milks and dairy beverages. Int Journal Dairy Technol, 63 (1), 1-15 (2010).

Picone, C., Cunha R. Interactions between milk proteins and gellan gum in acidified gels, Food Hydrocol, 24, 502-511 (2010).

Ramirez-Sucre, M. y F. Vélez-Ruiz, Physichemical, rheological and stability characterization of a cheramel flavored yogurt. Food Sci Technol, 51,233-241 (2013).

Shoji A. y otros siete autores, Viability of L. acidophilus microcapsules and their application to buffalo milk yoghurt, Food and Biopr Process, 91(1) 83-88 (2013).

Sendra, E. y otros cinco autores, Viscoelastic properties of orange fiber enriched yogurt as a function of fiber dose, size and thermal treatment, Food Sci Technol, 43, 708-714 (2010). 
Shah, N., Probiotic bacteria: Selective enumeration and survival in dairy foods, J. Dairy Sci, 83, 894-907 (2000).

Soukoulis, C. y otros dos autores, Enrichment of ice cream with dietary fiber: effects on rheological properties, ice crystallization and glass transition phenomena, Food Chem, 115, 665-671 (2009).

Steffe, J.F., Rheological Methods in Food Process Engineering, second ed. Freeman Press, East Lansing, 412 p. (1996).

Sultana, K. y otros cinco autores, Encapsulation of probiotic bacteria with alginate-starch and evaluation of survival in simulated gastrointestinal conditions and in yoghurt, Int J. Food Microbiol, 62, 47-55 (2000).

Tabilo-Munizaga, G. y G. Barbosa-Cánovas, Rheology for the food industry. J. Food Eng, 67, 147-156 (2005).

Tang, J. y otros dos autores, Gelling properties of gellan solutions containing monovalent and divalent cations, J. Food Sci, 62, 688-692 (1997).

Tamime, A.Y., Fermented Milks. Blackwell Science Ltd., Oxford, England (2006).

Tamime, A. Y. y R. Robinson, Yoghurt. Sci and Technol, Cambridge: CRC Press. (2000).

Vercet, A. y otros cuatro autores, Rheological properties of yogurt made with milk submitted to manothermosonication, J. Agricul Food Chem, 50, 6165-6171 (2002). 